\title{
Contre-culture et refus de la société hétéronormée dans Tal der fliegenden Messer (Ruhrtrilogie 1, 2008) de René Pollesch
}

Gegenkultur und Ablehnung der heteronormativen Gesellschaft in René

Polleschs Tal der fliegenden Messer (Ruhrtrilogie 1, 2008)

Counter-Culture and Rejection of Heteronormative Society in René Pollesch's Tal der fliegenden Messer (Ruhrtrilogie 1, 2008)

Emilie Chehilita

\section{OpenEdition}

Journals

Édition électronique

URL : https://journals.openedition.org/ceg/8756

DOI : $10.4000 /$ ceg. 8756

ISSN : 2605-8359

Éditeur

Presses Universitaires de Provence

Édition imprimée

Date de publication : 1 mai 2013

Pagination : 243-257

ISBN : 0751-4239

ISSN : 0751-4239

\section{Référence électronique}

Emilie Chehilita, "Contre-culture et refus de la société hétéronormée dans Tal der fliegenden Messer (Ruhrtrilogie 1, 2008) de René Pollesch », Cahiers d'Études Germaniques [En ligne], 64 | 2013, mis en ligne le 02 janvier 2020, consulté le 02 juin 2021. URL : http://journals.openedition.org/ceg/8756 ; DOI : https://doi.org/10.4000/ceg.8756 


\title{
Contre-culture et refus de la société hétéronormée dans Tal der fliegenden Messer (Ruhrtrilogie 1, 2008) de René Pollesch
}

\author{
Emilie CHEHILITA \\ Université Paris 10 - Nanterre
}

René Pollesch (*1962) a grandi en Allemagne de l'Ouest et a été formé, de 1983 à 1989, à l'Institut d'Études théâtrales appliquées de Giessen, par Andrzej Wirth et Hans-Thies Lehmann, élève en cela de l'école dite postdramatique. Il fut directeur artistique du Prater entre 2001 et 2007, salle située dans la Kastanienallee de Prenzlauer Berg à Berlin et dépendante de la maison-mère, la Volksbühne am Rosa-Luxemburg-Platz'. Depuis la saison 2000-2001, les pièces de Pollesch font partie du répertoire du théâtre, signe notable d'une reconnaissance de l'institution pour son travail d'auteur et de metteur en scène.

Depuis sa construction en 1914, la Volksbühne am Rosa-Luxemburg-Platz est une salle emblématique des expérimentations de la scène théâtrale berlinoise. Max Reinhardt et Erwin Piscator y ont laissé leur empreinte. Frank Castorf, directeur du lieu depuis 1992, continue de se positionner en réaction à la culture dominante - médias de masse et théâtre bourgeois ou commercial -, au moyen d'un travail de déconstruction/reconstruction d'œuvres souvent placées au panthéon de la culture officielle telles que Les Trois Sæurs d'Anton Tchekhov ou La Dame aux camélias d'Alexandre Dumas. Obtenir une représentation à la Volksbühne est en somme le label d'une culture en marge des représentations dominantes, mais qui ne s'en ferait pas moins le reflet, c'est-à-dire qui se vivrait à côté, en résonance, tout en ayant à cœur de revendiquer un positionnement révolutionnaire, au moins esthétique, le souhait d'un dynamitage des codes des représentations d'une époque. La Volksbühne se veut une "institution d'avant-garde ", un établissement qui

1 Le pareours de René Pollesch est présenté sur le site internet de la Volksbühne: http:/www.volksbuchne-berlin.de/english/volksbuchne/ensemble/directors/rene_polleseh/? PHPSESSID=d2a6ab191a3cc0fe7a9c2fa9c192b894 (consulté cn septembre 2012). 
produirait de la norme en même temps qu'il s'essayerait à briser les normes sociales, esthétiques, politiques prévalant à l'extérieur'.

Metteur en scène de ses propres textes, René Pollesch adopte dans sa démarche artistique une position du même ordre et également ambiguë : ses œuvres se font les reflets du temps et proposent à la fois un style singulier et des pensées qui cherchent à faire exploser tous les cadres. La plume et la baguette de metteur en scène de René Pollesch sont-elles pour autant les instruments d'une contre-culture, opposée à une culture des élites, à une culture de masse et/ou des médias ? Dans sa Ruhrtrilogie 1: Tal der fliegenden Messer (Trilogie de la Ruhr 1: La vallée des couteaux volants) créée en 2008, Pollesch puise dans l'univers du cinéaste américain John Cassavetes auquel il mêle une petite citation d'un film de Quentin Tarantino. Dans le discours, il prend position contre l'héritage brechtien mais son théâtre n'est pas dénué de procédés de distanciation. Ses revendications récurrentes, notamment contre le culte de la vedette au sein de la "société du spectacle », à laquelle il substitue la diva kitsch et camp, et contre l'évangélisme des sentiments qu'il rattache au socialisme, font de lui un auteur qui souhaite s'inscrire contre le discours culturel et philosophique dominant.

\section{Modèles et contre-modèles}

\section{S'inspirer de la contre-culture hollywoodienne de Cassavetes}

Pour assister à Tal der fliegenden Messer à la Volksbühne, le spectateur n'entre pas par les portes habituelles : les ouvreurs le guident au travers des escaliers qui mènent à la grande scène de ce théâtre. Entrant «à jardin », le spectateur découvre d'abord l'espace des coulisses qui ressemble à une loge : plusieurs portemanteaux supportent une grande quantité de costumes et des tables sont surmontées de grandes glaces encadrées d'ampoules allumées. Sur la scène, qui se trouve être aussi la salle, sont disposées sous un chapiteau aux tons rouges, et doté lui aussi d'ampoules allumées, des chaises de jardin en plastique pour accueillir les spectateurs. Juste en face du public se trouve un grand écran. Derrière le public, la régie occupe une baraque en bois, du même matériau que le podium situé côté cour et dont le fond de scène est couvert d'ampoules. Une voiture est placée à sa suite. Côté jardin, se trouvent une autre caravane, dont l'intérieur est agencé comme celui d'une loge, et dans son prolongement, une tente, en plastique bleu rayé de blanc, à l'intérieur de laquelle sont placés un canapé, des fauteuils et une table. Les spectateurs sont entourés d'un décor qui rappelle les différents espaces du film The Killing of a chinese bookie (Meurtre d'un bookmaker chinois, 1976-78) de Cassavetes dont Tal der fliegenden Messer s'inspire.

2 Voir l'article de Sylvie Arlaud dans la présente revue. 
Le titre de la pièce fait peut-être référence au film chinois et hongkongais House of the flying daggers (Le Secret des poignards volants) réalisé par Zhang Yimou en 2004, histoire d'amour et film d'arts martiaux, mais rien ne permet de l'affirmer avec certitude. Le lien à The Killing of a chinese bookie est, par contre, très prégnant. Pollesch et le scénographe Bert Neumann reproduisent les lieux essentiels du film : le tripot où l'on joue au poker (la tente), les loges des artistes (la caravane), la scène de spectacle avec ses barres verticales de type pole dance et ces petits promontoires trapézoïdaux (le podium) et la voiture. Le scénario de The Killing of a chinese bookie peut se raconter de manière brève : Cosmo Vitelli, propriétaire d'un club de striptease à Las Vegas, le Crazy Horse West, propose à ses clients des numéros de danses lascives, d'effeuillages et d'humour; il joue au poker et perd une très grosse somme d'argent qu'il ne peut rembourser; son adversaire lui propose de payer sa dette en tuant un bookmaker chinois ; il réussit cette mission et, blessé, retourne dans son club où l'attendent ses mafieux adversaires qui veulent tout de même sa mort ; Cosmo, sachant sa mort inévitable, fait l'annonce habituelle du spectacle qui débute.

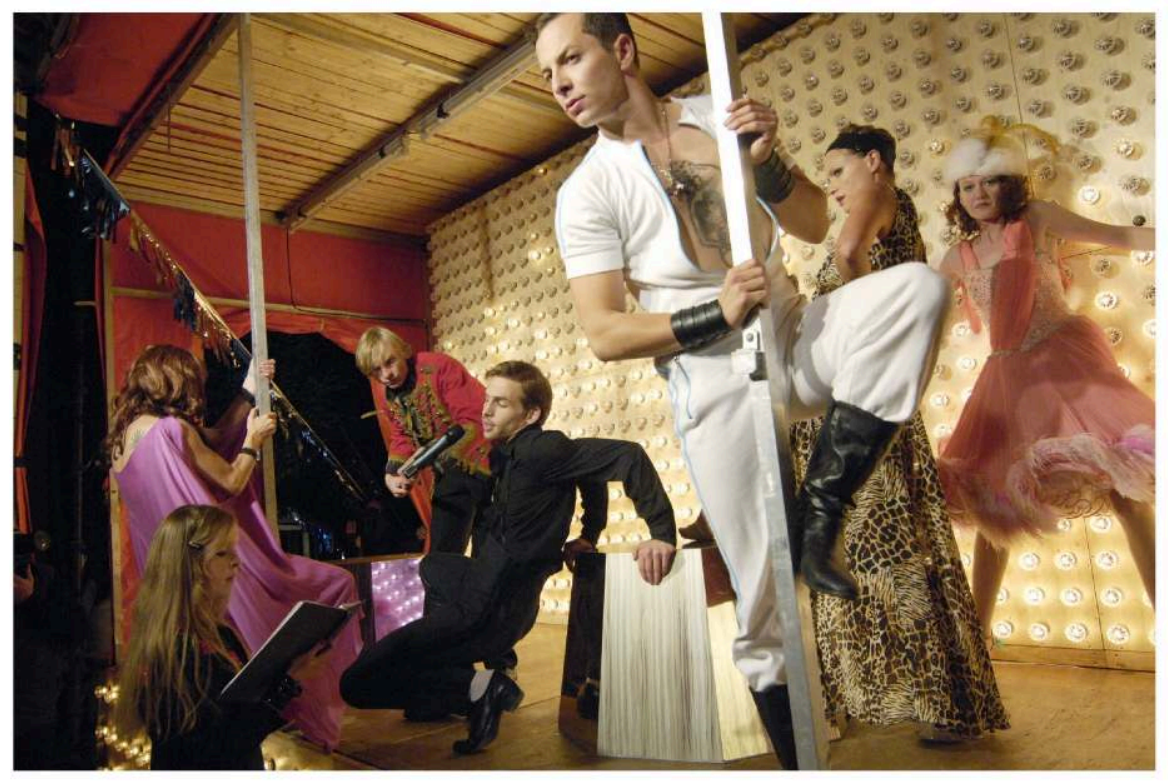

Le podium et ses danses lascives.

Ruhrtrilogie 1 de René Pollesch (2008). (C) Thomas Aurin.

L'air de la salle/scène de la Volksbühne est empli de la fumée des cigarettes que certains acteurs ont allumées dès avant le début de la pièce. L'acteur Trystan Pütter, en peignoir, plus tard dans une combinaison blanche, une chaîne en or autour du cou, fume cigarette sur cigarette. Entassés dans la 
caravane, certains cherchent leurs costumes, comme dans les vestiaires du club de strip-tease de Cosmo. Sous la tente, Cosmo donne à une actrice un sac en papier kraft rempli de billets de banque, comme à l'ouverture du film. Le personnage principal du film de Cassavetes est le plus souvent interprété par Christine Groß. En même temps, le visage de Pütter est proche de celui de l'interprète de Cosmo dans le film, Ben Gazzara, ce qui constitue un redoublement de la figure de l'acteur principal, pour ceux du moins qui ont connaissance du film. Ici aussi sont organisés des numéros, mais ce ne sont pas des strip-teases, seulement des danses accompagnées du texte à teneur théorique de Pollesch. Les trois femmes, Inga Busch, Nina Kronjäger et Christine Groß, dansent et sont rejointes par Martin Laberenz et Pütter. Le texte de Mister Sophistication qui, dans le film, propose un numéro sur la ville de Paris, est attribué un moment à Volker Spengler qui passe presque tout le spectacle dans la caravane-loge. Laberenz, en chemise et pantalon noir, est une sorte d'acolyte de Pütter. Tous les personnages, comme les comédiens, font partie de la même troupe, du même camp, celui du Crazy Horse. Les mafieux, ennemis de Cosmo, ne sont pas représentés, ou du moins pas clairement. On retrouve aussi les errances en voiture, les danseuses/prostituées accompagnant Cosmo au cours de celles-ci, avec une citation de la scène finale de Death Proof (Le Boulevard de la mort) de Tarantino dans laquelle une cascadeuse s'attache sur le capot d'une voiture, ses pieds liés aux rétroviseurs des portières avant et les bras devant elle comme pour voler. Le thème musical du film de Tarantino est d'ailleurs repris dans le spectacle. L'ensemble finit dans une fusillade, rappelant celle, chaotique, de la fin du film de Cassavetes lors du meurtre du fameux bookmaker chinois. La pièce n'est pas, dans son ensemble, un remake à la lettre du film de Cassavetes, mais plutôt une citation sous forme de clin d'œil admiratif et inclusif, qui sert à Pollesch de cadre pour ses propres expérimentations. Une forme de filiation s'établit ainsi entre des artistes en lutte contre les modèles esthétiques dominants de leurs époques.

Dans l'utilisation de la vidéo, des similitudes entre les travaux de Pollesch et Cassavetes sont repérables. La vidéo de la pièce propose un flux d'images en continu sur un seul grand écran, un très long plan-séquence en somme. La technique de la caméra à l'épaule, aujourd'hui typique du film américain indépendant, est exagérée dans le traitement de la vidéo chez Pollesch. La camerawoman, accompagnée du perchman, poursuit les comédiens, qui, suivis de près par la souffleuse, le texte à la main, courent d'un bout à l'autre de la scène. Les câbles qui sillonnent le plateau manquent parfois de faire tomber les techniciens. Le cadre de l'image sautille tout le temps, et, à l'intérieur de celui-ci, les comédiens ont la bougeotte. Dans les films de Cassavetes, l'acteur occupe une place centrale au point que les mouvements de la caméra semblent dictés par les interprètes dont le spectateur a souvent l'impression qu'ils improvisent alors même que le script est très écrit. Ces mouvements visibles et parfois secs de la caméra se retrouvent dans la vidéo de Pollesch. La saturation des couleurs, leur aspect trop criard et en quelque 
sorte irréel, les réglages qui paraissent approximatifs rappellent les lumières défectueuses et les halos scintillants et éblouissants qui envahissent l'image du night-club dans le film.

Tout comme Cassavetes ne s'opposait pas frontalement à la machine hollywoodienne dans ses films, Pollesch ne s'oppose pas frontalement à la «société du spectacle», et d'un point de vue esthétique, il propose une forme d'entertainment un peu décalé. Il ne s'agit pas pour autant d'adhérer à la théorie de la distanciation brechtienne, au contraire, c'est contre l'héritage de Brecht qu'il prend position.

\title{
Contre l'héritage brechtien
}

Il n'est pas rare d'entendre des metteurs en scène allemands dire que pour innover, il faut dépasser Bertolt Brecht et que monter un auteur que le monde du théâtre a longtemps considéré comme révolutionnaire ne serait pas la preuve d'un engagement "contre le consensus ». Pollesch imagine le millionnaire Josef Ackermann, président du conseil d'administration du Zurich Insurance Group, directeur exécutif de la Deutsche Bank, assistant à une représentation de L'Opéra de Quat'sous (Die Dreigroschenoper) de Brecht, et il se figure les pensées de ce dernier à l'écoute de la célèbre phrasedicton « Erst kommt das Fressen, dann kommt die Moral» (« D'abord vient la bouffe, ensuite vient la morale ») :

\begin{abstract}
Ackermann weiß, die da oben jammern ja wieder nur. Der kann sich auf den hohlen Jargon verlassen, den die Theater produzieren. Den unhinterfragten Glauben ans Leben, an die Moral, an die Psychologie. Oder einen diffusen Bereich von Kritik, der scheinbar allen offensteht. Ackermann verlässt sich auf das Missverständnis. Darauf, dass hier eh keiner mehr glaubt, dass da oben gegen den Konsens gesprochen wird, der ja gleichzeitig als Verständigungsgrundlage dient. Mit Brecht bringt man sich dabei um die Anstrengung, etwas Neues zu denken. ${ }^{3}$
\end{abstract}

Se référer à Brecht, c'est se tourner vers une étoile morte, un horizon indépassable et sclérosant. Usant d'un jeu de mot autour du VerfremdungsEffekt, effet de distanciation, Pollesch parle du «Brechts EntfremdungsEffekt », effet d'aliénation brechtien, et conclut à la muséification définitive du célèbre auteur allemand ${ }^{4}$. Ce dernier serait encore considéré dans le milieu du théâtre comme un écrivain révolutionnaire : grâce à ses textes, on pourrait créer des pièces qui changeraient notre rapport à l'art du théâtre et au monde. Mais cette conception se vérifie de moins en moins chez les jeunes

3 René POLLESCH, «Dialektisches Theater now! Brechts Entfremdungs-Effekt », Der Tagespiegel, 14. August 2006, in René POLLESCH, Liebe ist kälter als das Kapital, Hamburg, Rowohlt, 2009, p. 304.

4 «Verschleiern vor sich selbst müssen die Theater dann noch die Tatsache, dass das Zeug vielleicht nur deshalb passt, weil es schon mal funktioniert hat. Man bringt sich um die Anstrengung, etwas Neues zu denken und überhaupt zu denken. », ibid., p. 305. 
générations, à de rares exceptions près. Pollesch renchérit : Brecht semble être un auteur plus jeune que Schiller ou Shakespeare, mais il est tout aussi démodé. D'une part, parce que la «société du spectacle» et son versant le plus visible, les mass media, auraient, selon Pollesch, accaparé et galvaudé la distanciation : cette technique autrefois produite par la marge serait devenue une pratique courante à la télévision par exemple et notamment pour les publicités ${ }^{6}$. D'autre part, parce que le Lehrstück, la pièce didactique ou d'apprentissage, dans toute son ampleur serait impossible à réaliser dans le théâtre occidental actuel. Ce serait un «théâtre sans public » ${ }^{7}$ 《 $[\ldots]$ un théâtre qui abandonne simplement le public, ou les répétitions $[\ldots] »^{8}$. Le théâtre occidental ne serait pas prêt à assumer une telle radicalité et donc achopperait toujours à une utilisation réellement révolutionnaire de la pièce d'apprentissage. Cette interprétation du Lehrstück lui vient de l'enseignement d'Andrzej Wirth à l'université de Gießen'. Pollesch explique plus précisément la manière dont il s'est saisi de la pensée de son professeur : le but de son travail ne vise pas directement la communication, le public ne doit pas forcément comprendre tout ce qui est dit sur scène. Ce sont avant tout les acteurs qui doivent investir avec sérieux le thème qui les intéresse, de manière à interpeller et à intéresser les spectateurs. La communication avec le public, qui, selon certains critiques, n'intéresserait pas René Pollesch, n'est pas non plus un élément qu'il récuse, il ne la met simplement pas au premier plan ${ }^{10}$.

5 «Brecht ist Museum, und das ist Gott sei Dank auch die Praxis der Brecht-Erben. Die tun wenigstens nicht so, als wäre er keines. Im Gegensatz zur ganzen Pimp-my-Schiller- und Pimpmy-Shakespeare-Praxis. ", ibid.

6 Pollesch explique que dans une réclame pour 1'Oréal, les publicitaires choisissent de faire parler Penelope Cruz en allemand tout en lui laissant son accent espagnol, décision inverse de celle des distributeurs de cinéma pour un doublage en allemand. Le maintien de l'accent espagnol dans le premier cas serait une volonté de montrer l'actrice dans son naturel, c'est-àdire de la montrer comme elle est dans sa vie privée. Au contraire, cela produirait un effet de séparation entre la personne, son double publicitaire d'une part, et son double filmique d'autre part. La mise en parallèle de ces deux formes rendrait lisible la séparation théorisée par Guy Debord : l'homme, dans la société du spectacle, est séparé de sa vie, de l'action qu'il peut avoir sur celle-ci. Ce que René Pollesch constate, c'est la séparation de la star d'avec son image à l'écran. Le procédé de distanciation serait une pratique courante des médias mainstream; aussi est-il logique pour lui de ne pas employer ces mêmes moyens : « Daran muss ich immer denken, wenn Penelope Cruz in einer deutsch synchronisierten Shampoo-TV-Werbung deutsch mit spanischem Akzent spricht. Werbung muss sich selbst wahrscheinlich immer mit den falschen Entscheidungen belästigen, als so eine Art Dauerlehrstück in Unternehmensfragen. ", ibid., p. 301.

7 « ein Theater ohne Publikum », ibid., p. 303

8 « ein Theater, das einfach das Publikum wegließ, oder die Proben [...]», ibid., p. 301.

9 «Unser Professor Andrzej Wirth hat ein Jahr lang über Theater ohne Publikum, Theater ohne Probe geredet. ", René POLLESCH und Adel KARASHOLI im Gespräch mit Frank RADDATZ und Harald MÜLLER, "Verfremdung und jetzt ? ", in Brecht+Müller Theater. Brecht-Tage 2009, Berlin, Theater der Zeit, Recherchen 75, 2010, p. 14.

10 «Es wird manchmal über meine Arbeit gesagt, mich würde Kommunikation mit dem Publikum nicht interessieren. Aber das ist ein Missverständnis, es interessiert mich nachdrücklich. Ich interpretiere 'Theater ohne Publikum' aber so, dass die Arbeit der Leute im Theater schnurstracks auf Kommunikation zielt, dass man sich nicht so zurichtet, damit die da 
Le refus de faire de Brecht un père théâtral mène-t-il pour autant à l'abandon de tout procédé de distanciation? Rien n'est moins sûr car chez Pollesch, la distinction entre l'acteur et le personnage est souvent sujette à questionnement, comme dans de nombreuses productions dites postdramatiques. L'acteur parle de sa propre vie, il sort facilement du personnage qu'il incarne de très loin, les « rôles » passent d'un acteur à l'autre, ils sont en quelque sorte neutralisés car raconter une histoire n'est pas le propos de l'auteur. De plus, la notion de personnage se dissout entre l'interprète et son image filmique : le dédoublement en direct empêche l'adhésion à une quelconque fiction qui de toute façon n'est pas construite. La coexistence de l'image à l'écran et de la présence scénique désoriente le spectateur qui ne sait s'il doit regarder l'acteur à l'écran ou sur scène. C'est aussi une saturation sensorielle volontaire que produit le spectacle; le tropplein, qui singe la sollicitation médiatique de nos sociétés spectaculaires et marchandes, n'engendre pas une immersion du spectateur dans le spectacle, mais son incapacité au contraire à s'extraire de sa position de spectateur. Voir l'acteur à la fois sur scène et en gros plan sur l'écran, invisible de la scène car enfermé dans son conteneur et de face sur le grand écran, crée un effet d'étrangeté : désincarnation du corps car dissociation du corps et de son image à l'écran. Comme le remarque Frank Raddatz au cours d'un entretien avec le metteur en scène, la recherche de Pollesch n'est finalement pas si éloignée de celle de Brecht lorsqu'il explique que l'effet d'étrangeté est une volonté de rendre étranges des éléments ancrés dans le quotidien qui ne sont jamais remis en question :

POLLESCH: Mit dieser Art Theater versuchen wir, unsere Form der Desorientierung zu bearbeiten oder cinen schärferen Blick auf Konstruktionen dic als Normalität ausgegeben werden, zu bekommen. Also stellen wir das Normale in Frage und entlarven es als Konstruktion, indem wir die Herrschaftstechniken zeigen, dic darin eingegangen sind. [...]

RADDATZ: Das ist dic Verfremdungstheoric par excellence. Das Kernproblem, das dic Verfremdungstheoric lösen möchte, da das Alltäglichc das Gängige als Fremdes begriffen und gezcigt werden soll. ${ }^{11}$

Ce que récuse Pollesch en Brecht, c'est ce qu'il nomme le «théâtre littéraire $^{12} \%$. Même s'il admet que Brecht s'en est éloigné dans la théorie,

unten alles verstehen. Mir wäre wichtig, dass eben vor allem dic Leute, die auf der Bühne stehen, cine Kompetenz erwerben, für cin Thema, das sic interessiert, das sie beschäftigt, das sic ernsthaft betreiben und durch diese Ernsthaftigkeit dic Zuschauer dafür zu interessieren. Ich möchte also kein Theater ohnc dic Kommunikation mit dem Publikum machen, sondern ich würde nur sagen, die darf nicht im Vordergrund stehen. ", ibid., p.15.

11 René POLLESCH, «Penis und Vagina, Penis und Vagina, Penis und Vagina, René Pollesch über Geschlechterzuschrcibungen, das Normale als Konstruktion und die Thcoricfähigkcit des Alltags », in Frank RADDATZ, Brecht frisst Brecht. Neues Episches Theater im 21. Jahrhundert, Berlin, Henschel, 2007, p. 197.

12 «Es ist meine Hoffnung, dass man noch weiter weg kommt von diesem litcraturgeprägten Theaterbegriff. Und im Augenblick sche ich Brecht vor allem noch als Produzenten von Theaterliteratur. Aber viclleicht verschwindet seine Theaterliteratur bald von 
Pollesch trouve que les textes des pièces y restent attachés. Ce «théâtre littéraire » est celui qui raconte une histoire bien construite, qui montre des personnages qui n'ont rien en commun avec les acteurs qui les incarnent, les acteurs interprétant des situations et faisant intervenir des problématiques qu'ils ne connaissent pas et qui ne les intéressent pas personnellement; un théâtre qui choisit la plupart de temps de montrer l'unité du corps et de l'esprit, qui vise à ce que le spectateur se projette sur des figures qui évoluent sur scène. Pollesch cherche, à travers un style qui se rapproche du sampling en musique électronique ${ }^{13}$, à atteindre ce qu'il nomme l'abstraction ${ }^{14}$, réalisée en peinture et dont il voit les prémisses dans les écrits de Samuel Beckett. En somme, le refus de se poser en héritier du brechtisme n'est pas le signe qu'aucune trace de cet homme de théâtre qui a profondément marqué la théorie et la pratique théâtrales allemandes - à l'Ouest comme à l'Est - ne soit visible dans son travail d'auteur. C'est plutôt le reflet de son choix d'être indépendant, d'être un électron libre, de s'opposer à une culture théâtrale officielle dont Brecht serait devenu l'un des noms emblématiques - et que par exemple Castorf, en devenant lui aussi une référence, finirait également par incarner. On verra que Pollesch propose une démarche qui s'inscrit notamment en contrepoint de l'hyper-sexualisation de la femme chez Castorf, surtout perceptible ces dernières années.

Si ces modèles et contre-modèles peuvent placer Pollesch tout entier du côté de la contre-culture, dans une opposition à la culture mainstream, à la culture médiatique et à une culture théâtrale reconnue, qu'en est-il du contenu et des procédés récurrents de cette critique ?

der Bühne, und vielleicht rückt stattdessen seine Theatertheorie mehr ins Blickfeld. », ibid., p. 201.

13 « Die hierbei angewendeten Verfahren ähneln jenen, die in der Neuen Musik und in verschiedenen Sparten populärer Musik unter dem Begriff des Samplings, in der bildenden Kunst als Montage und Collage bekannt sind, welche aber für den Bereich der Literatur und der philosophisch-ästhetischen Diskussion noch immer kaum anerkannt werden. », Johann REISSER, « Archäologische Schnitte, kollidierende Wucherungen: Das post-bürgerliche Schauspiel des Selbst in René Polleschs Theater des Sagbaren », in Arthur PELKA, Stefan TIGGES (dir.), Das Drama nach dem Drama, Verwandlungen dramatischer Formen in Deutschlands seit 1945, Bielefeld, Transcript, 2011, p. 287.

14 «Es gab in der Malerei Tendenzen zur Abstraktion, also weg von diesen kohärenten, zusammenhängenden Menschendarstellungen. Warum ist im Theater der Versuch nich geglückt, keine Projektionsfläche mehr zu bieten für die Seele? », in Brecht+Müller Theater, op. cit., p. 30. 


\title{
Les cibles de la critique de René Pollesch
}

\author{
Contre la vedette de la « société du spectacle», la figure kitsch et \\ camp de la contre-culture gay
}

Les créations de Pollesch empruntent souvent à l'idée déjà ancienne dans l'histoire de la critique du capitalisme que le corps est une marchandise. Cette conception remonte aux premiers temps de la critique de la société industrielle par la pensée marxiste qui développe l'idée que le travailleur ne possède que sa force de travail, son propre corps, ses mains. Un siècle plus tard, avec la société de consommation et la production en série et à grande échelle d'objets manufacturés, vient la pensée que tout peut avoir une valeur marchande et donc que le corps peut se vendre. Si l'on ajoute à cela le développement des techniques de reproduction photographique et filmique, l'image du corps prend en réalité une valeur commerciale très importante. Pollesch reprend cette critique en la transposant au milieu qu'il connait le mieux, celui du théâtre :

\begin{abstract}
I: (in die Kamera) Jetzt müssten wir Cosmo eigentlich warnen! Der Typ von diesem Spielcasino will ihn anfixen! Wer viel Geld hat, kann spekulieren! Wer wenig Geld hat, darf nicht spekulieren! Wer nichts hat, muss spekulieren! Also wir hier müssen spekulieren mit dem, was wir haben in diesem Stripclub, mit unseren Körpern. Aber Cosmo darf nicht spekulieren! ${ }^{15}$
\end{abstract}

Le metteur en scène joue justement, par son utilisation de la vidéo, sur la séduction dont le comédien use et les différentes barrières entre monstration, démonstration et étalage. La trame que Pollesch choisit lui permet de travailler sur ces nuances : les univers de la boîte de strip-tease et des mafieux sont propres à ce jeu entre séduction involontaire et volontaire. Un des acteurs de l'équipe, Laberenz, a une beauté masculine très photogénique, de gros plans de son visage ou des muscles de ses bras reviennent fréquemment, tandis que les autres comédiens vantent sa beauté. De manière générale, dans les mises en scène de Pollesch, les acteurs deviennent des portemanteaux au sens littéral du terme : ils essaient des costumes, mais ces essayages semblent détachés de tout lien logique. Le costume "dit» un univers, mais il reste costume, strass et paillettes qui sont comme un ajout artificiel au corps qui les soutient. Et, plus encore, c'est le discours, généralement théorique, qui rend ces corps étrangers à eux-mêmes. Le type de costumes utilisé ${ }^{16}$ renvoie à

15 René POLLESCH, Liebe ist kälter als das Kapital, op. cit., p. 248.

16 Les deux hommes d'âge moyen revêtent une veste noire brillante aux bordures d'argent scintillant, par-dessus un pantalon et une chemise blanche. Spengler porte un collant de couleur chair et par-dessus un body à franges, et en vrac, pour les femmes, on voit passer une combinaison en résilles noires, avec, au-dessous un minishort et un soutien-gorge noirs, les épaules couvertes par une veste à paillettes argentée, une combinaison scintillante de pastilles d'or et d'argent, échancrée aux jambes, surmontée d'une coiffe aux tâches de léopard, avec un museau, des poils et de petites oreilles sur le haut du crâne, une autre combinaison se terminant 
l'univers du cabaret, de l'emphase festive qui en soi relève du kitsch, un kitsch de type Las Vegas, c'est-à-dire, surfait, artificiel, et utilisé comme artifice, en soulignant même cet aspect, sans volonté de le gommer. Mais, comme le souligne Patrick Cardon, ce jeu scénique avec le kitsch peut également devenir une modalité de reconnaissance de la culture gay :

Le kitsch est une modalité récurrente chez les gays. Si en effet le kitsch est la représentation de ce qui ne possc̀de plus ses fonctions originelles mais reste un objet décoratif décalé, les gays retrouvent la place que la société hétérocentréc Icur assignc : théâtralisation, sccondarisation, excentricité (inattenduc), non fonctionnalité, reproductibilité ćpuiséc. Le kitsch c'est l'ćtat d'un art devenu stérile auquel scul le décalage peut donner une nouvelle vic. ${ }^{17}$

En réinvestissant des objets désuets, une partie de la communauté gay reconnaît son identité et construit une contre-culture, en regard de la culture hétérosexuelle dominante. Ces déguisements qui ne fusionnent jamais avec le corps de l'acteur qui les porte, sont également une marque du camp, décrit par Susan Sonntag, qui se vit comme une attitude et perçoit les objets comme s'ils étaient toujours pris entre guillemets :

Le camp voit tout entre guillemets. Ce n'est pas une lampe, mais une « lampe»; pas une femme, mais une " femme". Perecvoir le camp dans les objets et les personnes, e'est comprendre l'être comme l'interprétation d'un rôle. C'est le plus lointain prolongement, dans le domaine de la sensibilité, du théâtre comme métaphorc de la vic. ${ }^{18}$

Les costumes ne sont pas les seuls éléments kitsch de ce spectacle. Le podium dont le fond est illuminé par des centaines d'ampoules qui s'éclairent pour former le mot «Love» ou pour figurer des flammes dansantes sont des éléments d'un glamour hollywoodien, d'un grand spectacle aujourd'hui un peu suranné. Quelques chansons de Françoise Hardy, comme «Le temps de l'amour» (de l'album Tous les garçons et les filles, 1962) et «Comment te

par un minishort à paillettes bordeaux assortic d'une traîne de plumes vertes attachée à la taille, un body noir avec unc veste et un chapeau de cowboy, un maillot de bain vert avec unc perruque rousse ou unc coiffe jaune surmontéc de grandes plumes blanches, un long peignoir rose en unc matière soycuse et satinéc, une robe rose aux contours voletants de plumes blanches et au col se terminant par une écharpe à gros pompons blanes, une chapka blanche, une robe léopard, une combinaison courte à paillettes noires avec cape rose, ctc. Même la tcchnique cst costuméc : lo perchman porte une veste de Monsicur Loyal.

17 Patrick CARDON, "Gay, Kitsch, Camp », in Isabclle BARBÉRIS ct Maric PECORARI (dir.), Kitsch et théâtralité, Effets et affects, Dijon, Éditions Universitaires de Dijon, 2012, p. 133.

18 Traduction de l'autcure de l'article : « 10. Camp secs cverything in quotation marks. It's not a lamp, but a 'lamp'; not a woman, but a 'woman'. To perccivc Camp in objects and persons is to understand Being-as-Playing-a-Role. It is the farthest extension, in sensibility, of the metaphor of life as theater, ", in Susan SONTAG, Notes on Camp, 1964. http://interglacial.com/ $\sim \sim$ sburke/pub/prose/Susan_Sonntag_-_Notes_on_Camp.html (page consultéc cn novembre 2012). 
dire adieu » (1968) ou le célèbre « Joe le taxi » de Vanessa Paradis (1987) colorent la bande-son d'une nostalgie de midinette. Ces citations d'une féminité populaire mais datée, de starlettes femme-enfant aux airs angéliques, sont également des références typiquement kitsch et camp, car il s'agit de la réappropriation d'éléments de la culture hétérosexuelle démodée, à laquelle on donne une seconde vie, ironique, au regard du discours qui l'accompagne notamment.

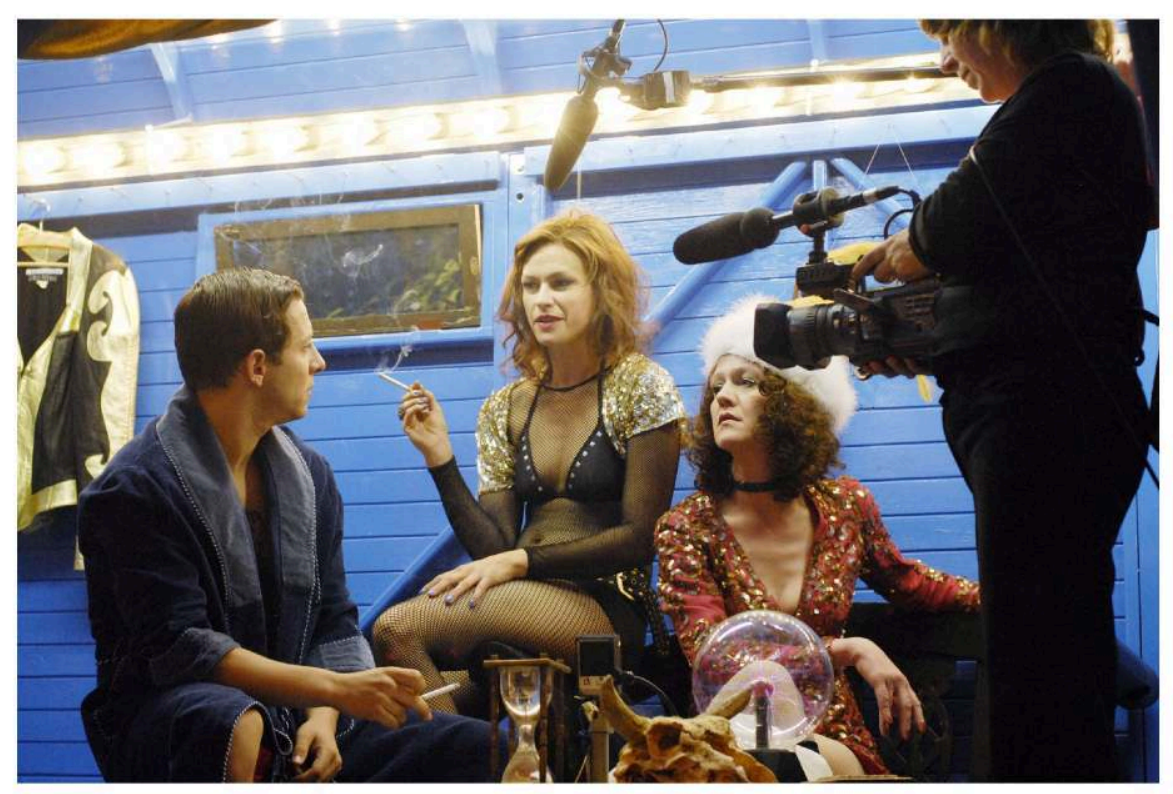

Le regard des divas.

Ruhrtrilogie 1 de René Pollesch (2008). C Thomas Aurin.

Les actrices choisies par Pollesch ne sont pas des lolitas éternellement jeunes, souriantes et lisses. Ce sont des femmes, au caractère bien trempé. Pour aller à l'encontre de la manière dont celles-ci sont utilisées dans l'histoire du théâtre, Pollesch choisit de ne pas en faire les porteuses uniques du sentiment et de l'émotion, éloignées des mouvements de la pensée, mais au contraire, de les faire discourir substantiellement. La féminité de ces actrices est davantage comparable à celle de la diva : image qui cristallise la représentation de la féminité pour une part de la communauté gay, une féminité camp impressionnante et qui a quelque chose de masculin, ou du moins que l'on attribue de manière sexiste au masculin ; une figure d'aspect autoritaire et qui ne se laisse pas facilement apprivoiser. Hormis Spengler, qui est une poupée à la fois grotesque et touchante, les deux autres hommes de Tal der fliegenden Messer ont un côté précieux : dandy éphèbe pour l'un et 
mafieux chic pour l'autre. De la même manière qu'il substitue au spectacle bien huilé le dérèglement de la machine, Pollesch substitue à la star glamour la star en trop-plein, celle qui refuse la starification liée, selon lui, à la pensée petite-bourgeoise. Pour reprendre les termes d'Isabelle Barbéris, le metteur en scène opère par le biais de la citation une «mise au second degré de la théâtralité » :

À ce titre, les objets kitsch qui encombrent les mises en scène d'un Frank Castorf, d'un René Polleseh, d'un Thomas Ostermeier mais aussi d'un Roméo Castellucei, les pièces d'un Carmelo Bene, d'un Fassbinder, d'un Thomas Bernhard font figures de mise au second degré de la théâtralité : ils sont comme les reliques de l'ancien théâtre illusionniste déposées, étalées, au fond présentées sur la scène postmoderne. Ils sont les traces d'une illusion morte, qu'il s'agisse de celle de l'american way of life et de ses objets périssables... ou celle du théâtre d'illusion - deux utopies du passé dont la scène contemporaine opère l'anamnèse. ${ }^{19}$

Certes, il s'agit de citations-recyclages, caractéristiques des cultures postmoderne et postdramatique, cependant, cette opération n'est pas purement esthétique, elle sert un discours dérangeant : Pollesch « déromantise » les relations à tous les niveaux, autant amoureux, amical que simplement de courtoisie, selon lui, les problèmes des autres ne nous touchent pas. Si la musique est ostensiblement sentimentale et pourrait être interprétée comme le fruit d'une nostalgie romantique naïve, le texte de Pollesch contrecarre et anéantit cette sentimentalité adolescente.

\section{La critique de l'amour}

La culture judéo-chrétienne est un des socles de la culture européenne. Déprécier la valeur que l'on donne à l'amour dans nos sociétés capitalistes et libérales, c'est notamment s'opposer aux médias de masse et à leurs représentations du bonheur, symbolisé en particulier par le couple amoureux hétérosexuel. S'opposer à l'amour comme salut, c'est s'opposer aussi à deux mille ans d'histoire du catholicisme. C'est dire que l'amour n'est pas le lien commun entre les êtres, lien de toute façon inexistant selon le metteur en scène. Lorsqu'il s'attaque à la notion d'amour, Pollesch récuse à la fois les représentations mainstream de l'hétérosexuel blanc et les fondations de la solidarité universelle socialiste :

I: Und dazu ist es ganz wichtig zu sagen, dass ich nicht gerade ein Problem mit der Liebe habe, jetzt im Moment, womit der Satz so gerne neutralisiert wird: Dass jemand nur gerade ein Problem mit der Liebe hat, sich aber dann doch ganz gern in eine Liebesgeschichte einreiht. Im Gegenteil, ich leg auf sie überhaupt keinen Wert. Mit Liebe ist gar nichts zu erreichen. Und das kann man mal sagen, ohne für neurotisch oder zynisch oder ironisch gehalten zu werden. Das sagt

19 Isabelle BARBÉRIS, in Isabelle BARBÉRIS et Marie PECORARI (dir.), Kitsch et théâtralité, Effets et affects, op. cit., p. 12. 
auch niemand aus Enttäuschung: dass die Liebe nichts erreichen kann. Die lieben sich doch alle. Die Typen, die man eigentlich töten müsste, die lieben doch auch ihre Kinder und ihre Mütter. Das kann doch nicht im Ernst das sein, was uns alle verbindet, dieser Dreck. Die Mutterliebe kann doch nicht das sein, was uns verbindet, nein, die Arbeit, die schwer ist, unheimlich schwer! Uns verbindet nicht die Rede vom Team von Alexander Kluge, wenn der nach acht Minuten doch wieder nur den einen Namen sagt: Rainer Werner Fassbinder. Das verbindet niemanden, ein Name. Wir haben nicht einen Namen, wir sind keine Gattung. Und kein Name steht stellvertretend für diese Gattung. ${ }^{20}$

Derrière la critique de l'amour comme but ultime, symboliquement et explicitement présent dans une majorité des productions fictionnelles ou commerciales de l'idéologie capitaliste et libérale dominante, se profile la critique de cette dernière. L'amour ne pourrait en aucun cas réconcilier les êtres humains entre eux et ne devrait donc pas être porté aux nues par cette société. L'amour entre les hommes ne serait qu'un leurre car ce sentiment ne siègerait qu'au sein d'une personne et donc se réduirait à un sentiment tourné vers soi, une attention logique et naturelle de l'homme à lui-même et non aux autres. Les déclarations d'amour intempestives que se font les comédiens vont dans ce sens ; de manière complètement inattendue, inopinée et sans raison d'être, les déclarations fusent et ne semblent être mues que par le hasard: c'est une spontanéité qui laisse déborder un besoin de consolation, une attraction mise sur le même plan que les autres actions, comme celle de chercher un slip dans les vestiaires. L'amour devient anodin.

En même temps qu'il est l'un des quelques auteurs de théâtre à critiquer frontalement et de manière très explicite le capitalisme, Pollesch tient un discours d'artiste. La question qui revient toujours cherche à cerner ce qui nous touche profondément, ce qui nous atteint. Cette critique de l'amour rejoint la "critique artiste ${ }^{21}$ " du capitalisme, telle qu'elle a été développée dans les années 1970 en Europe et aux États-Unis, c'est-à-dire porteuse de l'idée que l'amour, sous la forme véhiculée par les représentations majoritaires, ne serait qu'une fabrication du Capital pour mieux faire la promotion de ses marchandises. Cette idée que l'amour serait le seul palliatif que l'ordre économique aurait trouvé pour soutenir et maintenir le niveau de la misère humaine sous sa domination affleure souvent sous la plume de l'auteur :

[...] ebenfalls Baudrillard: „Das Evangelium der Sentimentalität", das Daueroperieren mit dem Begriff der Liebe, dem nicht nur bedeutungsschwersten, sondern auch "schwammigsten Wort unserer Sprache“. Baudrillard, ernst genommen auf einer Bühne, würde die Lesbarkeit der Veranstaltung, was Liebe und Leben betrifft, kolossal einschränken und zu erheblichen Missverständnissen führen, vor allem bei Beibehaltung einer Darstellungspraxis, die auf Psychologisierung und Ästhetisierung setzt und dadurch erst ihre ganze neutralisierende Kraft gewinnt. Theateraufführungen, in

20 René POLLESCH, Liebe ist kälter als das Kapital, op. cit., p. 294.

21 Voir Luc BOLTANSKI et Ève CHIAPELLO, Le nouvel esprit du capitalisme, Paris, Gallimard, 1999. 
denen gesichert von der Liebe, wie von einer ,allgemeinen Verteilungs- und Integrationsform, vor der alle gleich sind" gesprochen wird, neutralisieren vielleicht Folgendes: die Liebe ist nur das Abgeschmackteste, was der Kapitalismus hergeben konnte. Das Geld wäre so viel schöner als Bereich, der allen offen steht, wenn da nicht dieser Kapitalismus wäre, der immer nur Liebe will. $^{22}$

Mais la critique de l'amour concerne également le socialisme, Pollesch cite à ce propos l'essayiste allemand Dietmar Dath qui parle d'un «type sentimental de socialisme ${ }^{23}$ ", valorisant une nature humaine aux sentiments évangéliques. Le metteur en scène récuse la croyance en les vertus de l'amour, de la compassion et de la pitié afin de sauver l'humanité de son égoïsme. La critique de l'amour rencontre aussi une critique de la morale et plus largement de l'idéologie, ce qui inscrit la parole de l'auteur dans l'air du temps, en écho au discrédit général jeté sur les idéologies à la fin du $X X X^{e}$ siècle.

Pollesch développe des thèses perturbantes, qui laissent au spectateur un goût amer dans la bouche, il est poussé dans ses retranchements et s'interroge : serait-il vrai que la vie des autres ne me touche pas ? Je ne chercherais une relation amoureuse que parce que j'ai précisément un problème avec le sentiment amoureux ? Il est sûr que l'auteur s'oppose à une culture de plus de deux mille ans, qui voit dans l'amour universel une forme de salut, ainsi qu'à une culture straight ${ }^{24}$, opposée elle-même à la culture gay, en donnant, entre autres aux femmes des rôles de penseuses et non de midinettes simples d'esprit. Elles ne sont pas non plus les uniques sujets qui cristallisent le désir, les hommes y ont aussi une forte place. C'est également la culture petite-bourgeoise et bourgeoise bohème que l'auteur attaque de plein fouet en prenant à partie son auditoire, notamment dans une tirade de Pütter $^{25}$ qui qualifie littéralement les spectateurs de "nouilles kitsch» (Kitschnudeln), ce qui pourrait bien s'adresser aux jeunes gens branchés, aux positions politiques de gauche qui sont celles de la majeure partie de son public. Si, grâce à l'influence du réalisateur américain indépendant John

22 René POLLESCH, « Requiem fürs Programmheft. Zum Tod von Jean Baudrillard» (2007), in René POLLESCH, Liebe ist kälter als das Kapital, op. cit., p. 306.

23 «I: [...] eine sentimentale Sorte von Sozialismus [...]», in René POLLESCH, Liebe ist kälter als das Kapital, op. cit., p. 241.

24 Straight est un terme anglais qui signifie hétérosexuel, mais peut aussi vouloir dire « droit », c'est-à-dire sans courbe, « franc », « en ordre », « direct », « logique ». La plurivocité du mot nous renseigne sur le regard porté par la langue et donc la culture sur l'hétérosexualité ; elle est ce qui est conventionnel en somme.

25 «Tr: Diese Kitschnudeln hier denken sonst immer, sie könnten sich die Selektion als was Schönes erzählen. Diese Kitschnudeln, die denken, jeder könnte geliebt werden. Das funktioniert nicht mehr. Wir brauchen andere Berührungen. Berührungen, die vielleicht nicht so warm sind wie die von dem Typen, mit dem ich die Kinder habe, aber die vielleicht kalt genug sind, um sie der Welt als eine Form von Solidarität entgegenzuhalten. Und zu sagen, ich will die Berührungen kalt, mit den Frauen, die ihre Kinder erziehen und es sehr sehr schwer haben, und nicht mit dem Typen, mit dem ich sie habe. », ibid., p. 292. 
Cassavetes, Pollesch s'oppose à la culture mainstream, à l'impérialisme culturel américain et à sa « monoforme ${ }^{26}$ » tout en réinvestissant ses codes, il combat aussi l'actuelle culture de gauche, à la mode, qui est toujours surplombée par « le jargon de l'homme blanc hétérosexuel ${ }^{27}$ » qu'il confronte à ces femmes qui « ont la vie très, très dure » au nombre desquelles il compte la journaliste féministe et membre de la Rote Armee Fraktion Ulrike Meinhof.

Pollesch lutte contre un certain nombre de courants culturels et idéologiques dominants, au sein d'une institution reconnue pour de tels procédés. Même s'il finit par créer un style, voire un système, le discours de Pollesch échappe à la récupération totale car il est difficile à embrasser tout entier. Le discours est si dense, surtout à entendre pour la première fois au sein d'un théâtre et prononcé de plus à une vitesse éclair, les sujets, les références se succèdent sans discontinuer, au point qu'on en retient surtout l'énergie, le souhait de faire exploser les formes habituelles pour laisser place à un débat inachevé, la colère de crier que l'on n'adhère pas aux évidences contemporaines.

26 Terme créé par Peter WATKINS pour son essai critique sur les médias qu'il écrit dans sa langue maternelle, l'anglais, en 2003 et met en ligne la même année sur son site internet : http://pwatkins.mnsi.net. Texte traduit et publié en français sous le titre Media crisis aux éditions Homnisphères en 2004. La «monoforme» est un ensemble de techniques de montage et de narration le plus communément employé par ce que Watkins nomme les MMAV, mass media audiovisuels : mouvements de caméra incessants.

27 « weiße[r] männliche[r] heterosexuelle[r] Jargon », ibid., p. 305. 